

Culture \& Society: Journal of Anthropological Research

VOL. 1 NO. 2 DESEMBER 2019

http://culture.ppj.unp.ac.id

Email: culture@ppj.unp.ac.id

ISSN: 2686-343X (E-ISSN) 2686-3421 (P-ISSN)

DOI: https://doi.org/10.24036/culture/vol1-iss2/16

\title{
Makna Gerakan Silat Harimau Damam Syekh Kukut
}

Dedi Suryadi ${ }^{1}$ Eka Vidya Putra ${ }^{2}$

${ }^{1,2}$ Universitas Negeri Padang

Email: dedisuryadi4321@gmail.com, ekavidyaputra@gmail.com

\begin{abstract}
Abstrak
Penelitian ini bertujuan menjelaskan makna gerakan Silat Harimau Demam Syekh Kukut. Penelitian ini dianalisis menggunakan teori interpretivisme simbolik oleh Clifford Geertz yang menyatakan bahwa makhluk yang bergantung kepada kebudayaan yang dihasilkannya sendiri namun analisisnya adalah bukan ilmu eksperimen untuk mencari hukum, melainkan sebuah ilmu yang besifat interpretatif untuk mencari makna. Metode yang digunakan ialah Pendekatan kualitatif dengan tipe etnografi, dan menggunakan teknik purposive sampling dalam pemilihan informan. Teknik pengumpulan data dilakukan dengan cara observasi dan wawancara. Data dianalisis dengan mengacu pada model analisis etnografi. Hasil penelitian ini menunjukkan bahwa gerakan yang dipakai dalam perguruan Silat Harimau Damam Syekh Kukut yaitu, (1). Salam sambah memiliki makna berserah diri pada yang pencipta (2). Balabeh memiliki makna bahwa seorang pesilat sudah siap untuk melakukan latihan atau menerima serangan (3). langkah, dalam perguruan terdiri atas langkah ampak dan langkah tigo (4). simpia dan bermakna memperindah gerakan dan menjaga keseimbangan apabila kena serangan dari lawan (5). gelek bermakna cara menghindar dari serangan lawan.

Kata Kunci: Makna, Gerakan, Interpretivisme simbolik

\section{Abstract}

This study aims to explain the meaning of the Shakh Kukut Tiger Fever Silat movement. This study was analyzed using the theory of symbolic interpretiveism by Clifford Geertz who stated that creatures that depend on the culture they produce themselves but whose analysis is not an experimental science to search for law, but an interpretive science to search for meaning. The method used is a qualitative approach to the type of ethnography and using purposive sampling techniques in the selection of informants. Data collection techniques carried out by means of observation and interviews. Data were analyzed by referring to the ethnographic analysis model. The results of this study show that the movements used in the damam syelh katut martial arts school are, (1). Salam sambah have the meaning of surrender to the creator (2). Balabeh has the meaning that a pesilat is ready to conduct training or accept attacks (3). step, in college there are learn step four and step three (4). simpia and meaningfully beautify the movement and maintain balance when attacked by an opponent (5). gelek means to avoid the opponent's attack.
\end{abstract}

Keywords: Meaning, Movement, Symbolic interpretation

\section{\begin{tabular}{|l|l|l|} 
Received: October 8, 2019 & Revised: October 23, 2019 & Published: October 29, 2019 \\
\hline
\end{tabular}}

Culture \& Society: Journal of Anthropological Research Vol. 1, No. 2, Th. 2019 


\section{Pendahuluan}

Kebudayaan juga merupakan suatu peralatan simbolik bagi pengontrol perilaku sehingga proses kebudayaan harus dipahami, diterjemahkan dan diinterpretasi. Bahasa simbolik dari kebudayaan bersifat umum, fungsi simbolik universal dan manusia tidak dapat memahami kebudayaan suatu masyarakat tanpa fungsi ini. Interpretasi makna simbolik kebudayaan merupakan pemahaman dalam mengartikan sebuah simbol yang dihasilkan dari sebuah kegiatan. Manusia sebagai makhluk budaya mengandung pengertian bahwa manusia menciptakan budaya dan kemudian budaya memberikan arah dalam hidup dan tingkah laku manusia(Mardotillah \& Zein, 2017). Kebudayaan merupakan hasil dari adanya ide-ide dan gagasan-gagasan yang kemudian mengakibatkan terjadinya aktivitas lalu dikembangkan dan menghasilkan suatu karya. Salah satu kebudayaan yang lahir dari tanah air adalah silat(Rakhmat \& Fatimah, 2016). Silat adalah bela diri asli Indonesia yang kini telah mendunia. Istilah silat sendiri sudah dikenal oleh masyarakat Asia Tenggara, mulai dari Indonesia, Malaysia, Brunei Darussalam, Singapura, Thailand dan Filipina. Di Indonesia, istilah "pencak" banyak dipergunakan di daerah Jawa, sedangkan "silat" digunakan di Sumatera, Semenanjung Malaya dan Kalimantan. Dari sejarahnya sendiri silat berkembang dari ilmu bela diri dan seni tari rakyat, menjadi bagian dari pendidikan bela negara untuk menghadapi penjajah asing. Pada sekarang ini silat dijadikan sebagai bela diri dan juga sebagai sebuah seni gerakan, baik untuk tarian maupun perlombaan.

Perkembangan zaman yang cukup pesat, banyak timbul jenis beladiri yang tidak hanya berasal dari Indonesia. Berkembangnya jenis beladiri dari luar Indonesia menyebabkan kurangnya masyarakat indonesia untuk mendalami beladiri silat itu sendiri. Silat adalah olahraga yang didasarkan pada ketangkasan menyerang dan membela diri, baik memakai atau tanpa senjata(Moeliono, 1990). Penulis berpendapat silat adalah sebuah seni bela diri mengandung dua makna yaitu seni dan pembelaan diri. Seni melihat pada keindahan gerak, pola langkah, bahkan seni dalam pencak silat dimana keindahan gerak dan langkah dipadu menjadi sebuah gerakan yang dijadikan untuk pertunjukan, Sedangkan bela diri adalah unsur utama dalam silat, intisari dari keahlian seseorang dalam pembelaan diri, membela diri dalam silat menggunakan teknik-teknik, kaidah dan filosifi dalam silat yang dianut dalam diri seseorang pesilat.

Daerah Minang khususnya kota Solok sudah berkembang tradisi silat. Hal ini dapat dilihat dari banyaknya perguruan silat yang didirikan oleh masyarakat Kota Solok. Salah satunya yaitu Perguruan Silek Harimau Damam Syekh Kukut, yang berdiri pada tahun 50-an. Perguruan ini berdiri karena dahulunya daerah Kota Solok merupakan benteng pertahanan di masa perjuangan. Dari hasil pengamatan yang dilakukan oleh peneliti mengambarkan bahwa silat Harimau Damam Syekh Kukut masih eksis atau masih berjalan sampai sekarang. Pentingnya untuk mempelajari silat karena di dalam latihan silat terdapat pelajaran karakter yang mendukung pesilat untuk bekal menghadapi kehidupan nyata, yang berisi nilai dan norma yang bisa membantu dalam kehidupan. Ada berbagai gerakan yang ada dalam silat yang terdiri beberapa unsur yaitu kudo-kudo, gelek, balabeh, sandiang, dan gabuak. Semua unsur merupakan hasil dari harmonisasi antara rasa, kekuatan dan kelembutan seorang pesilat dalam setiap gerakan yang dilakukan, Kurangnya pemahaman dikalangan pesilat tentang konsep-konsep pemikiran silat, gerak, atau istilah yang ada di dalamnya membuat nilai-nilai dan makna tradisi Minang makin lama makin hilang.

Perguruan Silat Harimau Damam Syekh Kukut mengajarkan tentang gerakan, ketuhanan, kematangan jiwa, prilaku, kepemimpinan dan cara berpikir serta memandang kehidupan. Dalam silat, banyak terkandung nilai-nilai filosofi, baik itu gerak (langkah dan serangan). Penelitian yang relevan dengan penelitian ini adalah penelitian yang dilakukan oleh Agus Heryana, yang berjudul "Pencak Silat Ameng Timangan di Jawa Barat, Hubungan Antara Ajaran dan Gerak Aming Timbangan" penelitian ini dilakukan dengan pendekatan kualitatif dengan metode deskriptif, yakni suatu suatu metode yang memaparkan data apa adanya yang kemudian

\section{Culture \& Society: Journal of Anthropological Research Vol. 1, No. 2, Th. 2019}


dianalisis. Hasil penelitian Pencak silat Ameng Timbangan diciptakan R. Moezni Anggakoesoemah bersumber pada ajaran Timbangan. Ajaran Timbangan bukanlah petunjuk teknis untuk melakukan jurus tertentu, melainkan ajaran kerohanian Islam. Di dalamnya dibahas mengenai trilogi Islam, yaitu Iman-Islam-Ihsan. Ajaran ini menjadi jiwa dalam gerak lahiriah Ameng Timbangan(Heryana, 2018).

Kemudian penelitian yang relevan dengan penelitian ini adalah penelitian yang dilakukan oleh Wisnu Andhika, Jurusan Sosiologi, Fakultas Sosial dan Imu Politik, Universita Bangka Belitung, yang berjudul "Hakikat Simbol pada Perguruan Pencak Silat Tawakal dan Tapak Suci Pangkalpinang" penelitian ini menggunakan metode penelitian kualitatif deskriptif. Teknik pengumpulan data pada penelitian berupa wawancara, observasi, dan dokumentasi. Hasil penelitian ditemukan berbagai bentuk-bentuk simbol yang terdapat pada perguruan pencak silat Tawakal dan Tapak Suci dan pada tiap-tiap simbol mengarah pada bentuk kekuasaan akan simbol yang ada.

Kekuasaan simbolik bekerja dengan menggunakan simbol-simbol sebagai intrumen "pemaksa" terhadap kelompok subordinat yang turut berperan memproduksi tatanan social sesuai dengan keinginan kelompok dominan. Praktik dominasi simbol akan terlihat ketika mereka yang didimiasi menerima begitu saja simbol-simbol yang ditawarkan oleh pihak dominan(Wisnu, 2016). Terdapat kesamaan antara penelitian yang akan dilakukan dengan studi ini, yakni sama-sama membahas tentang makna yang terdapat dalam silat. Namun juga terdapat perbedaan disini, jika di dalam penelitian yang dilakukan oleh Wisnu Andhika yaitu melihat hakikat simbol pada perguruan pencak silat, berbeda dengan penelitian yang akan peneliti lakukan yakni pada penelitian ini peneliti lebih mefokuskan kepada makna gerakan silek tuo harimau damam syekh kukut, yang berada di Kota Solok. Dari paparan di atas peneliti tertarik meneliti mengenai Makna Gerakan Silat Harimau Damam Syekh Kukut, karena di dalam Gerakan Harimau Damam Syekh Kukut terdapat makna yang belum banyak diketahui orang dan dari situlah peneliti tertarik untuk melakukan penelitian ini.

\section{Metode Penelitian}

Pendekatan yang dilakukan dalam penelitian ini adalah pendekatan kualitatif, yakni penelitian yang menghasilkan data deskriptif mengenai kata-kata lisan maupun tulisan dan tingkah laku yang dapat diamati dari orang-orang yang diteliti. Pendekatan kualitatif bertujuan untuk mendeskripsikan sebuah fenomena sosial yang diteliti, namun yang terpenting adalah menjelaskan dan mendeskripsikan makna dari fenomena yang muncul(Bungin, 2007). Peneliti ingin memperoleh informasi mendalam dari informan, yang telah ditetapkan untuk memperoleh data yang diperlukan tentang Silek Harimau Damam Syekh Kukut. Serta pada gerakannya yang di pelajari dalam belajar Silek Harimau Damam Syekh Kukut kota solok. Pemilihan informan dilakukan secara purposive sampling, dalam artian peneliti menentukan informan berdasarkan tujuannya untuk untuk mengumpulkan data dilapangan yang sesuai dengan kebutuhan dan tujuan penelitian. Peneliti mencari informasi kepada informan dengan cara pergi langsung melihat realita yang ada dilapangan. Adapun kriteria informan adalah orang yang terlibat dalam Silek Harimau Damam Syekh Kukut yang terdiri dari guru tuo, Asisten guru, dan anggota seperguruan Silek Harimau Damam Syeah Kukut.

Observasi diartikan sebagai kegiatan penelitian melalui pengamatan dan pencatatan secara sistematik terhadap berbagai gejala yang tampak pada objek penelitian(Basrowi \& suwandi, 2008). Metode ini dilakukan untuk melihat kegiatan atau aktifitas yang terdapat dalam perguruan Silek Harimau Damam Syekh Kukut. Observasi yang akan peneliti lakukan adalah observasi partisipasi. Observarsi partisipan yaitu suatu bentuk observasi di mana pengamat (observer) secara teratur berpartisipasi dan terlibat dalam kegiatan yang diamati. Jadi, penulis juga ikut dalam setiap latihan yang dilakukan oleh anggota perguruan silat harimau damam syehk kukut. Dalam hal ini pengamat mempunyai fungi ganda, sebagai peneliti yang tidak diketahui dan dirasakan oleh anggota yang lain, dan kedua sebagi anggota kelompok, peneliti berperan

\section{Culture \& Society: Journal of Anthropological Research Vol. 1, No. 2, Th. 2019}


aktif sesuai dengan tugas yang dipercayakan kepadanya(Yusuf, 2014)Setelah melakukan observasi peneliti melakukan wawancara salah satu teknik yang digunakan unrtuk mengumpulkan data. Secara sederhana dapat dikatakan bahwa wawancara (interview) adalah suatu kejadian atau proses interaksi antara pewawancara (interviewer) dan sumber informasi atau orang yang diwawancara (interviewee) melalui komunikasi langsung(Yusuf, 2014). melalui wawancara peneliti mengumpulkan informasi tentang gerakan Silek Harimau Damam Syekh Kukut serta mencari tahu makna yang terdapat dalam gerakan tersebut.

\section{Hasil dan Pembahasaan}

Silat merupakan sebuah beladiri yang di kenal di Minangkabau, Silat merupakan sistem beladiri yang diwariskan oleh nenek moyang sebagai budaya bangsa Indonesia sehingga perlu dilestarikan, dibina, dan dikembangkan(Kriswanto, n.d.). karena pemuda Minangkabau mayoritas pergi merantau pasti bisa silat. Seorang yang ingin belajar silat harus menemui guru silat terlebih dahulu, Silat atau pencak silat merupakan sebuah kebudayaan beladiri warisan leluhur budaya bangsa. Oleh karena itu Silat di Minangkabau terkait erat dan bersumber dari budaya dan adat istiadat etnis Minangkabau, dan mengandung nilai-nilai etika dan estetika, serat dengan makna kearifan, keteladanan, kependekar-an, dan keluhuran budi pekerti. Silat di Minangkabau digunakan bukan untuk berkelahi tetapi lebih digunakan untuk menjalin hubungan atau silaturrahmi, menjaga diri, membentengi diri, serta mempertahankan diri dari berbagai ancaman (Irwandi, 2017) dan harus melengkapi syarat yang di berikan oleh guru, pada perguran silat harimau damam syarat yang harus di lengkapi yaitu: syarat bukan hanya sekedar bahan material aja, tetapi di setiap syarat tersebut memiliki makna tersendiri yang berguna untuk guru dan seorang murid yang mau latihan.

Pertama, Ayam jantan Biriang yaitu seekor ayam memili paruh berwarna kuning dan kakinya pun bewarna kuning, gunanya untuk melihat kemaun seorang pesilat dalam melakukan latihan silat sesuai dengan pemaparan oleh seorang guru dalam perguruan silat harimau damam syekh kukut seorang pesilat yang mau ikut latihan, Seseorang yang belajar dan berlatih pencak silat dengan niat yang tulus, sungguh-sungguh dan menghayati setiap hal yang diberikan gurunya tentu akan mengamalkan sikap dan perilaku yang sesuai dengan nilai-nilai filsofi dan ketuhanan( $\mathrm{Aj}, 2010)$. harus melakukan pembantai ayam terlebih dahulu, supaya seorang guru bisa melihat apa kah seorang murid benar sungguh-sungguh atau tidak serius dalam melakukan latihan, dan melihat potensi yang ada di dalam diri seorang yang mau laitihan.

Kedua, Pisau melambangkan bahwa seorang yang mau latiahan silat, harus berserah diri ke gurunya supaya dapat belajar silat, dan pisau tersebut menggambarkan supaya seorang pesilat harus berhati-hati dalam bertindak, karna akan berakibat fatal bagi dia. Ketiga, Kain putiah sakauang menandakan bahwa sebelum latihan seorang murid masih putih seperti kain putih ini melambangkan bahwa warna putih melambangkan kesucian dalam diri seorang pesilat dalam menerima pelajaran dari seorang guru, dan seorang murid benar-benar bersungguh-sungguh dalam berlatih

Keempat, Camin dan sikek sesuai dengan fungsinya cermin untuk melihat diri seseorang seberara mahirnya seorang pesilat seorang pesilat harus seperti cermin, di ibaratkan terbuka kepada ke semua orang, dan sisir dilambangkan bahwa apabila seorang murid melenceng dalam latihan, maka sisir di ibarakat untuk meluruskan hati seorang murid untuk bersungguh-sungguh dalam melakukan latihan.

Ketiga, Siriah sakabek Langkok, satu ikat siriah lengkap melambangkan wahwa kita yang mau mengikuti latihan harus membawa satu ikat siriah lengkap supaya kita bisa beradaptasi dengan teman seperguruan yang telah lebih lama latihan dengan kita, dan memandakan bahwa kita murid baru untuk mendapat bimbingan dari kakak perguruan kita. Setelah melengkapi syarat untuk masuk dalam perguruan maka, seorang murid telah sah untuk menjadi murid dalam perguruan tersebut, Dimensi olah tubuh merupakan gerakan anggota badan yang ditekankan pada pembentukan otot-otot agar kuat namun lenturkegiatan yang(Heryana, 2018) di

\section{Culture \& Society: Journal of Anthropological Research Vol. 1, No. 2, Th. 2019}


lakukan oleh seseorang yang telah sah dianggap sebagai seorang murid yaitu belajar teknik gerakan dasar yang dilakukan dalam perguruan silat harimau damam syekh kukut, dalam perguruan silat harimau damam syekh kukut ini tidak ada tingkatan pada muridnya jadi yang membedakan hanya. Murid yang sudah lama relatif gerakan tubuhnya lebih luwes dan bertenaga dibandingkan dengan murid yang baru bergabung dalam perguruan ini(SAKTI, 2016). Silat Harimau Damam Syekh Kukut termasuk dalam silat tua maka jatwal latihannya pada malam hari yang jatwal latihannya yaitu hari kamis sesudah magrib dan sabtu malam sesudah magrib.

Gerakan Yang Dipakai Dalam Perguruan Silat Harimau Damam Syekh Kukut Pertama, Makna Salam Sambah Sebuah gerakan yang membuat posisi seorang pesilat berdiri tegak dan melipat tangannya, seolah-olah seperti orang yang lagi melaksanakan sholat, walaupun posisi nya berdiri tegak diam namun posisi tersebuat memiliki makna yaitu merendahkan diri dari pencipta dan mementa doa simbol dari salam jo sambah tersebut memiliki makna yaitu makna yang mengambarkan bahwa sebelum melakukan latihan atau tanding, seorang pesilat harus berserah diri pada sang pencipta, merendahkan diri dan meminta doa. Salam jo sambah juga berarti kita memohon izin kepada Allah SWT dan juga kepada langit dan bumu, ini dikarenakan kita berada di bawah langit dan berpijak di atas bumi. Bertaqwa kepada Tuhan Yang Maha Esa dan berbudi luhur, Yang artinya seorang pesilat berkewajiban melaksanakan segala perintah dan menjahui larangan agama (Moh. Nur Kholis, 2016). Umumnya Pencak Silat mengajarkan pengenalan diri pribadi sebagai insan atau makhluk hidup yang percaya adanya kekuasaan yang lebih tinggi yaitu Tuhan Yang Maha Esa(Sandi, n.d.) Menurut Geertz simbol dapat dilihat sebagai konsep-konsep yang dianggap oleh manusia sebagai pengkhasan sesuatu yang lain yang mengandung kualitas-kualitas analis-logis atau melalui asosiasi-asosiasi dalam pikiran dan fakta. Selain itu manusia memberikan makna kepada setiap kejadian, tindakan atau objek yang berkaitan dengan pikiran, gagasan dan emosi. Pada gerakan salam dan sambah ini melambangkan pada kesiapan kita dalam menerima ilmu yang diberikan. salam dan sambah juga meluruskan niat kita dalam menerima ilmu tersebut agar pada saat latihan tidak mengalami cedera atau sulit dalam mendalami setiap Gerakan.

Kedua, Balabeh Setelah melakukan salam sambah maka seorang pesilat melakukan gerakan balabeh. Balabeh yaitu sebuah gerakan yang mengubah gerakan tangan sesuai dengan gerak kaki untuk membentu stan atau posisi gerakan. seorang pesilat melakukan gerakan tangan satu di depan dan tangan satu lagi dekat dengan badan, yaitu melambangkan bahwa tangan yang di depan menunjukan bahwa seorang pesilat sudah siap untuk melakukan gerakan, dan tangan di dekat badan berfungsi sebagai tameng atau pengaman badan apabila ada serangan yang sasaranya ke badan simbol dari Balabeh yaitu melambangkan bahwa seorang pesilat sudah siap melakukan latiahan dan apabila seorang pesilat sudah melakukan gerakan balabeh maka ke waspadaan kita harus dijaga karna kita sudah siap untuk menerima serangan. Menurut Geertz simbol dapat dilihat sebagai konsep-konsep yang dianggap oleh manusia sebagai pengkhasan sesuatu yang lain yang mengandung kualitas-kualitas analis-logis atau melalui asosiasi-asosiasi dalam pikiran dan fakta. Selain itu manusia memberikan makna kepada setiap kejadian, tindakan atau objek yang berkaitan dengan pikiran, gagasan dan emosi. Pada gerakan balabeh menandakan bahwa seorang pesilat sudah siap melakukan latihan dan sudah siap untuk menerima serangan.

Ketiga, langkah dalam perguruan Silat Harimau damam syeah kukut menggunakan beberapa pola langkah yaitu langkah ampek (langkah empat) dan langkah tigo (langkah tiga). Masing-masing langkah tersebut memiliki makna yang khas yaitu langkah empat, merupakan gerakan pola serang yang di gunakan untuk bermaen atau latihan dengan teman seperguruan gerakan langkah empat digunakan untuk berlatih dengan teman satu perguruan. langkah empaat lebih menekankan kepada seni dari gerakan silat itu sendiri. Selain itu ada juga langkah tiga yang merupakan gerakan pola serang yang di gunakan dalam pertarungan yang mempokuskan kepada serangan simbol dari langkah tergantung seperti apa yang di pakai seorang pesilat, kalau langkah empat memiliki makna langkah yang di gunakan dalam latihan dengan teman satu perguruan, karna sebelum melakukan langkah empat terlebih dahulu melakukan salam jo 
sambah, apabila dalam latiahan teman seperguruan kena pukulan atau serang, maka niat seorang pesilat tidak boleh berubah, bahwa mereka hanya berlatiahan tampa mencederai teman seperguruan. Perasaan menunjuk pada bagaimana perasaan pada suatua anggota system sosial (anggota kelompok) tentang hal-hal, peristuwa-peristiwa tempat tertentu. (Moh Nur Kholis, 2016). Sedangkan langkah tiga di namakan langkah parang dalam perguruan silat harimau damam syekh kukut, karna langkah tiga ini biasanya pola serangan yang menyerang bagian vital saja, tampa memberikan kesempatan kepada orang lain untuk melakukan serangan balik Menurut Geertz simbol dapat dilihat sebagai konsep-konsep yang dianggap oleh manusia sebagai pengkhasan sesuatu yang lain yang mengandung kualitas-kualitas analis-logis atau melalui asosiasi-asosiasi dalam pikiran dan fakta. Selain itu manusia memberikan makna kepada setiap kejadian, tindakan atau objek yang berkaitan dengan pikiran, gagasan dan emosi. Pada gerakan langkah tergantung gimana situasi seorang pesilat yang di hadapinya, biasanya langkah empat di pakai untuk permainnan beradat atau juga bermain sama teman satu perguruan sedangkan langkah tigo biasanya di pakai untuk pertandingan silat.

Keempat, Simpia merupakan gerakan yang digunakan untuk elakan serangan dengan menggunakan sistem kaki bersilang dengan mengnakan putaran pinggul dan dapat membantu serangan balik dengan gaya tipuan, simpia simbol dari Simpia bahwa untuk memperindah gerakan dan juga menjaga keseimbangan dari pesilat apabila terkena serangan dari lawan. Simpia ini tidak hanya kita temui pada silat saja, di kehidupan sehari-hari gerakan simpia ini juga banyak kita temui seperti menjaga keseimbangan ketika akan tersungkur atau mau jatuh, gerakan simpia inilah yang menjadi penjaga keseimbangan badan kita.

Kelima, Gelek dalam istilah silat harimau damam syekh kukut yaitu elakan, Gelek merupakan gerakan yang di gunakan sebagai elakan, yang di gunakan dalam latihan atau pertandingan silat, baik serangan pukulan atau tendangan dengan menggunkana kekuatan otot pinggul, di dalam latihan silat yang pertama kali harus dikuasai oleh seorang pesilat yaitu gerakan gelek. Gelek juga diartikan sebagai gerakan menghindar dari serangan lawan. Gerakan gelek ini merupakan dasar dari seorang pesilat, karena di dalam silat harus bisa dengan cepat menghindar dan menangkis serang yang diberikan lawan. Pada gerakan silek di perguruan syekh kukut ini setiap gerakannya memiliki makna dan simbol yang menandakan maksud dari gerakan itu sendiri. Gerakan itu secara tidak langsung juga dilakukan pada kegiatan sehari-hari seperti pada gerakan simpia. Geertz dalam teori interpretifisme simbolik juga menjelaskan bentuk primer dari simbol itu melalui bahasa. Selain bahasa manusia juga berkomunikasi melalui simbol tarian, lukisan, gestur, gerak-gerik dan lain sebagainya. Pada silek yang ada di perguruan syekh Kukut ini para pesilat juga melakukan gerakan yang memiliki makna di setiap gerakannya. Makna tersebut juga berguna pada kehidupan sehari-hari baik berhubungan kepada sang pencipta maupun terhadap pergaulan sesama manusia.

Putuih kaji Silat Setelah seorang murid sudah memahi gerakan silat yang di ajarkan guru, maka tahap terakir pesilat yaitu putuih kaji. Putiah kaji yaitu sebuah ritual yang di lakukan seorang pesiat untuk mendapatkan pemahaman tentang silat lebih dalam serta menandakan bahwa seorang pesilat benar-benar sudah mahir dalam silat biasa di sebut dengan pandeka. apabila seorang pesilat di katakana sebagai pandeka dia sudah bisa mengamalkan ilmu padi, karna ilmu padi semakin berisi semakin tunduk. itu lh yang harus dipakai seorang pandeka

\section{Kesimpulan}

Seorang yang ingin masuk dalam perguruan Silat Harimau Damam Syekh Kukut untuk belajar silat harus melengkapi syarat yang di berikan guru syarat yang harus dilengkapi yaitu: Ayam jantan Biriang, Pisau, Kain putiah sakabuang, Camin dan sikek, Siriah sakabek Langkok kegiatan yang di lakukan oleh seseorang yang telah sah dianggap sebagai seorang murid yaitu belajar teknik kerakan dasar yang dilakukan dalam perguruan Silat Harimau Damam Syekh Kukut. Gerakan serta makna dalam Perguruan Silat Harimau Damam Syekh Kukut Makna Salam Sambah bermakna merendahkan diri dari pencipta dan meminta doa, Balabeh bermakna

\section{Culture \& Society: Journal of Anthropological Research Vol. 1, No. 2, Th. 2019}


melambangkan bahwa seorang pesilat sudah siap untuk melakukan gerakan, Langkah menggunakan pola langkah ampek dan langkah tigo, Simpia bermakna memperindah gerakan dan menjaga keseimbangan badan, Gelek gerakan yang digunakan sebagai elakan. Putuih kaji Silat Setelah seorang murid sudah memahami gerakan silat yang diajarkan guru, maka tahap terakhir pesilat yaitu putuih kaji. Putiah kaji yaitu sebuah ritual yang dilakukan seorang pesilat untuk mendapatkan pemahaman tentang silat lebih dalam serta menandakan bahwa seorang pesilat benar-benar sudah mahir dalam silat biasa disebut dengan pandeka

\section{Daftar Pustaka}

Afrizal Sandi, Ari. (2017). Pencak Silat As A System. JOM FISIP 4 (1) 1-12

Aj, O. (2010). Bunga Rampai Pencak Silat Memahami pencak silat secara jernih. Jakarta: Raja Grafindo

Basrowi, \& suwandi. (2008). Memahami Penelitian kualitatif. Jakarta: Rineka Cipta.

Bungin, B. (2007). Penelitian kualitatif. Jakarta: Kencana.

Heryana, A. (2018). Pencak Silat Ameng Timbangan Di Jawa Barat: Hubungan Antara Ajaran Dan Gerak Ameng Timbangan. Patanjala: Jurnal Penelitian Sejarah Dan Budaya, 10(1), 131. https://doi.org/10.30959/patanjala.v10i1.337

Irwandi. (2017). Perkembangan Pola Pendidikan Silat Pauh di Perguruan Silat Singo Barantai. Analisis Sejarah, 6(2), 120-126

Kriswanto, E. S. (n.d.). Sejarah dan Perkembangan Pencak Silat Teknik-Teknik dalam Pencak silat Pengetahuan Dasar Pertandingan Pencak Silat. Yogyakarta :Pustakabarupress

Mardotillah, M., \& Zein, D. M. (2017). Silat: Identitas Budaya, Pendidikan, Seni Bela Diri, Pemeliharaan Kesehatan. Jurnal Antropologi: Isu-Isu Sosial Budaya, 18(2), 121-129. https://doi.org/10.25077/jantro.v18i2.62

Moeliono. (1990). Kamus Besar Bahasa Indonesia. Jakarta: Depdiknas.

Nur Kholis, Moh (2016) Aplikasi Nilai-Nilai Luhur Pencak Silat Sarana Membentuk oralitas Bangsa. Jurnal SPORTI 2 9(2), 76-79

Rakhmat, P., \& Fatimah, J. M. (2016). Makna Pesan Simbolik Non Verbal Tradisi Mappadendang Di Kabupaten Pinrang. Jurnal Komunikasi KAREBA, 5(2), 331-348. Retrieved from http://journal.unhas.ac.id/index.php/kareba/article/viewFile/1911/1069

Sakti, P. O. (2016). Pencak Silat Tradisional Dan Anak Muda Perkotaan. Skripsi, Fakultas Ilmu Sosial Dan Ilmu Politik Universitas Lampung

Sandi, A.A. (n.d.). Pencak Silat Sebagai Sistem (Studi Kasus Pencak Silat Pangean). JOM FISIP 4(1), $1-12$.

Wisnu, A. (2016). Hakikat simbol pada perguruan pencak silat tawakal dan tapak suci pangkalpinang. skripsi. Fakultas Ilmu Sosial Dan Ilmu Politik Universitas Lampung.

Yusuf, M. (2014). Metode Penelitian Kuantitatif, Kualitatif dan penelitian gabungan. Jakarta: Pranadamedia Group. 